\title{
战 \\ É POSSÍVEL UM DIREITO SEM ESTADO? REFLEXÕES SOBRE A EXPERIÊNCIA HISTÓRICA DO DIREITO HEBRAICO NA ÉPOCA DA DIÁSPORA
}

\author{
Lúcio Flávio de Castro Dias*
}

RESUMO: Este trabalho critica a tese do positivismo normativista que afirma que o Estado e o Direito formam uma unidade indissociável. Para isso, apresenta a experiência histórica da sobrevivência do Direito Hebraico na época da Diáspora como exemplo de Direito válido e eficaz sem que existisse na época o Estado hebreu que a ele deveria corresponder, na ótica normativista.

PALAVRAS-CHAVE: Direito. Estado. Positivismo normativista. Direito Hebraico. Diáspora.

RESUMEN: Este documento critica la teoría del positivismo normativo que establece que el Estado y el Derecho forman una unidad inseparable. Por esta razón, se presenta la experiencia histórica de supervivencia Del Derecho hebreo en el momento de la Diáspora como un ejemplo de Derecho válido y eficaz sin que existíra en aquél momento el Estado hebreo que se le debía correspondir, en la perspectiva del positivismo normativo.

PALABRAS CLAVE: Derecho. Estado. Positivismo normativo. Derecho hebreo. Diáspora.

\section{Introdução}

Para o positivismo normativista, o Estado e o Direito são duas faces de uma mesma moeda. A Teoria Pura do Direito, ou normativismo, ao tentar limpar o fenômeno normativo de suas contradições e antinomias, atacou também a suposta dualidade Estado/Direito, estabelecendo a sua unidade indissociável.

-Advogado, Analista Legislativo da Câmara dos Deputados, aluno do Curso de Especialização em Processo Legislativo do

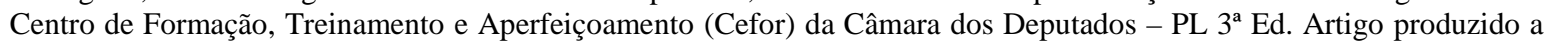
partir de trabalho apresentado para aprovação na disciplina Teoria do Processo Legislativo. lucio.dias@ camara.gov.br. 
Este trabalho pretende fazer uma crítica a essa tese, abordando a questão da possibilidade da existência de um Direito sem Estado pelo exame da sobrevivência do Direito hebraico nas condições da Diáspora, quando o povo judeu foi disperso pelo mundo todo e deixou de existir um Estado hebreu.

\section{A unidade do Estado e do Direito, na visão normativista}

O positivismo, em sua vertente normativista, estabeleceu para si próprio o que considerava a tarefa hercúlea da "limpeza dos estábulos de Áugias" da filosofia do Direito de sua época, de forma a dar um fundamento seguro à Ciência do Direito.

Nesse esforço, primeiro extremou o direito positivo do direito natural, e a seguir combateu os dualismos "direito público/direito privado", "direito subjetivo/direito objetivo", e outros dualismos congêneres, unificando essas supostas dualidades, culminando com a supressão teórica do dualismo entre Estado e Direito, considerados como faces da mesma moeda, como assinala Machado Neto:

Também unificação é a sorte do dualismo Estado e Direito. Esta é uma consequiência essencial do purismo epistemológico de Kelsen, pois o Estado não há de ser visto, na perspectiva da ciência jurídica, nem como realidade social (natureza), como o enfrenta a sociologia, nem como sistema ideal (valor) de organização e governo como o encara a filosofia política ou a ética.

Ao purismo metodológico-jurídico, o Estado somente se pode apresentar como uma ordem jurídica (MACHADO NETO, 1984. p. 45).

Kelsen, expoente máximo dessa corrente, fez uma crítica radical da concepção dualista do Estado e do Direito existente na época em que estabeleceu as bases da sua Teoria Pura do Direito. Após verificar que "a dualidade de Estado e Direito é, na verdade, um dos fundamentos da ciência política e da jurisprudência modernas", ele buscou demolir esse conceito, afirmando:

Contudo, esse dualismo é teoricamente indefensável. O Estado como comunidade jurídica não é algo separado de sua ordem jurídica, não mais do que a corporação é distinta de sua ordem constitutiva.

(...)

Como não temos nenhum motivo para supor que existam duas ordens normativas diferentes, a ordem do Estado e sua ordem jurídica, devemos admitir que a comunidade a que chamamos de "Estado" é a "sua" ordem jurídica (KELSEN, 2005. p. 263)

Ao combater a idéia de que o Direito é "criado" pelo Estado, e que este, portanto, tem de existir anteriormente para poder formatar aquele, ele rebatia:

(...) e o Direito é criado pelo Estado apenas na medida em que seja criado por um órgão do Estado, ou seja, na medida em que o Direito seja criado de acordo com o Direito. A 
afirmação de que o Direito é criado pelo Estado significa apenas que o Direito regulamenta a sua própria criação (Idem, p. 285).

Nesse sentido, o estudo da sobrevivência do Direito hebraico na época da Diáspora, desde quando o Estado judeu existente foi aniquilado pelas legiões romanas, em 70 d.C., até o momento em que a Organização das Nações Unidas determinou a criação do Estado de Israel, em 1948, pode ser analisado com proveito em confronto com a tese normativista.

\section{O Direito hebraico: breve notícia de suas origens históricas até a Diáspora}

Segundo a tradição judaica, o Direito hebraico teria sido dado diretamente por Deus a Moisés no topo do Monte Sinai. A pesquisa histórica revela, no entanto, que a Torá não é obra de um só homem, e nem sequer todos os livros foram redigida simultaneamente, como registra Gilissen:

Na realidade, o texto data de diferentes períodos; certas partes (nomeadamente as que dizem respeito aos Patriarcas) remontariam ao início do segundo milênio; a maior parte das outras teriam sido redigidas em períodos diferentes entre os séculos XII e V; a forma definitiva não dataria senão de cerca de 450 anos antes de Cristo. Esse problema de datação continua no entanto muito controvertido ( GILISSEN, 2003, p. 68).

Após o êxodo do Egito, os hebreus teriam peregrinado pelo deserto durante quarenta anos, até a morte de Moisés, quando, sob a liderança militar de Josué, expulsaram de Canaã os seus habitantes originários, ocupando os seus territórios. Nos primeiros tempos em Canaã, segundo Sinaida de Gregório Leão, prevaleceu uma estrutura de tribos autônomas, que não tinham um governo centralizado. As decisões relativas aos problemas internos e aos litígios entre membros do grupo eram tomadas por um conselho de anciãos. O único elo de ligação entre as tribos era a identidade cultural e religiosa, materializada pela presença em Shilo da Arca da aliança (“Aron Hakodesh"), contendo os mandamentos. Nos períodos em que havia ameaça de invasão por inimigos, era nomeado um chefe militar, denominado "Shohet", ou seja, "juiz".

Com a invasão de Canaã, no séc. XII a.C., pelos filisteus, um povo mais avançado do ponto de vista da tecnologia militar, as tribos hebréias sentiram a necessidade de estabelecer uma liderança permanente, que conduzisse uma guerra de longa duração contra os novos invasores. Nessa época, foi instituída a monarquia, sendo o rei ungido pelos sacerdotes e recebendo deles os poderes de comando, tendo sido escolhido como primeiro rei Saul, que empreendeu várias campanhas vitoriosas contra o novo invasor que havia se estabelecido no interior de Canaã.

Uma série de divergências entre Saul e os sacerdotes abriu caminho para a assunção de um novo rei, David, ungido primeiro secretamente como sucessor escolhido pelos sacerdotes e, após a morte de Saul em batalha, elevado à realeza, embora não fosse descendente do antigo monarca. 
Com David, o Estado hebraico é unificado e centralizado como reino de Israel, tendo como capital a cidade de Jerusalém. Ele consegue tornar a monarquia hereditária, estabelecendo no trono o seu filho favorito, Salomão, sob o qual o reino de Israel alcançou o seu máximo poderio.

Após a morte de Salomão, com a subida ao trono de seu filho Roboão, uma série de revoltas populares contra a imposição de pesados tributos ao povo levou à divisão do reino em dois, Israel e Judá. Divididos, os reinos se mostraram uma presa fácil dos grandes impérios orientais da época. Em 722 a.C., a Assíria tomou e destruiu o reino de Israel. Em 586 a.C., os babilônios, que haviam submetido os assírios, conquistaram o reino de Judá, destruindo inteiramente Jerusalém e o Templo de Salomão, transformando a região numa província da Babilônia, para onde foi deportada a maior parte dos judeus (Exílio Babilônico).

Em 586 a.C., os persas, por sua vez, submeteram a Babilônia, e Ciro, rei daquele povo, permitiu a volta dos judeus a Jerusalém e foi nomeado governador da província um judeu, Neemias, que reconstruiu as muralhas de Jerusalém e promoveu uma série de reformas sociais, cancelando as dívidas dos camponeses pobres e devolvendo a estes as terras que lhes tinham sido confiscadas. Neemias, com o auxílio de Esdras, compilou e sistematizou a Torá e reorganizou o sistema judiciário de Judá, com base no Direito hebraico, com a formação da Grande Assembléia ("Knesset Hagdolá"), um corpo jurídico-religioso formado por 120 membros, escolhidos por Esdras e pelos escribas dentre os chefes das famílias mais importantes e sacerdotes, sendo presidido por um Sumo Sacerdote. A função da Grande Assembléia era distribuir a justiça e resolver problemas internos do povo, tendo sido responsável pela compilação e canonização dos livros bíblicos (LEÃO, 1998)

Em 333 a.C., Alexandre, o Grande, rei da Macedônia, conquista a Pérsia, estendendo o seu domínio sobre todas as províncias anteriormente pertencentes a esta. Alexandre concedeu autonomia religiosa e jurídica aos judeus. Em sua época, desapareceu a Grande Assembléia, substituída pelo Sinédrio, que, segundo Leão, reviveu a instituição judiciária fundada por Moisés, ou seja, o conselho de setenta anciãos, presidido por um Sumo Sacerdote, cujos componentes eram eleitos por sufrágio universal dentre as pessoas mais sábias, moderadas e populares das diversas localidades, sem distinção de classe social, política e econômica. Além da função interpretativa da lei religiosa, civil e criminal, o Sanhedrin possuía plena autoridade legislativa e administrativa, julgava conflitos entre os outros tribunais, e certas infrações cujo julgamento era de sua competência privativa. As decisões do Sanhedrin, resolvidas segundo a tradição, quando inexistisse norma específica atinente ao caso concreto, tinham força de lei em todo o país (idem).

Com a morte de Alexandre, o Grande, seu império dividiu-se entre os seus generais Ptolomeu e Selêuco, que deram origem a duas novas dinastias. A Judéia estava originalmente sob o domínio ptolomaico, que manteve praticamente inalterado o sistema jurídico anterior. No ano de 
201 a.C., no entanto, a região passou para a órbita selêucida, em que o poder do imperador era absoluto e não permitia qualquer forma de representação popular. O Sumo Sacerdote passou a ser nomeado diretamente pelo imperador, que controlava inteiramente também o Conselho Judaico. O império selêucida mostrou-se opressor, sobrecarregando a população com pesados tributos e interferindo em sua liberdade religiosa, o que levou à revolta popular conhecida como Guerra dos Macabeus, derivada do nome de um dos líderes militares, Judas, o Macabeu.

A revolta foi bem sucedida e o reino de Judá passou a ser governado pela família de Judas, o Macabeu, destacando-se nesse período o governo de João Hircano, que expandiu as fronteiras da Judéia a quase toda a região atualmente conhecida como Palestina e Jordânia. Uma disputa pelo poder entre descendentes dos Macabeus abriu caminho para a dominação romana, que apoiou uma das facções e a levou à vitória, obtendo em troca a cessão de vários territórios judeus e a submissão a Roma, findando o período de independência nacional da Judéia.

No ano 70 de nossa era, uma revolta judaica foi reprimida pelos romanos com extrema violência, com a destruição da Jerusalém e do Segundo Templo. No entanto, as revoltas continuaram a surgir esporadicamente, até que em 135 d.C. o imperador Adriano enviou suas tropas à Judéia e quase toda a região foi destruída. Após esses acontecimentos nefastos para eles, os judeus foram espalhados pelo mundo. Iniciava-se a Diáspora, que durou até a fundação do moderno estado de Israel, em 1948.

\section{A sobrevivência do Direito hebraico na Diáspora}

O Direito hebraico sobreviveu, com maior ou menor amplitude, durante o período da Diáspora, com os judeus tentando manter sua identidade étnica, cultural e religiosa no exílio, e criando instituições autônomas dentro dos países para onde foram obrigados a se exilar. Dessa forma, há uma continuidade essencial entre o Direito hebraico do período anterior e o deste novo período: as normas vigentes são as mesmas, e as instituições do exílio retomam características das instituições jurídicas pré-existentes.

Parte importante dessa resistência se concentrou na instituição das cortes rabínicas, que passaram a desempenhar papel decisivo na vida das comunidades de exilados judaicos. Leão assim caracteriza essa resistência:

Na Diáspora, os rabinos e lideres do povo começaram a lutar junto aos governos estrangeiros pela autonomia judicial das cortes rabínicas judaicas e pela independência da Lei Judaica. No início, como se depreende de vasta literatura de "responsas", as cortes rabínicas tinham competência para julgar matérias da lei civil, como direito de propriedade, obrigações, família e sucessões, e para decidir os problemas relativos à administração da comunidade judaica local. Em alguns centros, a competência se estendia até mesmo à 
matéria criminal. Em geral, essa situação de autonomia existiu até o século XVIII, apesar das restrições que em certas épocas e lugares eram feitas aos judeus. Evidentemente, paralelamente à autonomia para julgar, as cortes rabínicas tinham o poder de aplicar sanções, como arresto, multa pecuniária, penas privativas de liberdade, e o banimento do indivíduo do seio da comunidade ("herem”). Em alguns casos, era necessário a intervenção da autoridade do país para possibilitar a execução da pena imposta, como é o caso da pena de morte (LEÃO, 1998, p. 41).

Os líderes das comunidades judaicas no exílio zelavam implacavelmente pela aplicação do Direito hebraico à sua comunidade. Um dos mecanismos para tanto era a interdição, de caráter religioso, que impedia que os judeus recorressem às cortes do país onde se encontravam nos litígios entre eles. Mesmo nos lugares em que o Estado no qual habitavam não reconhecia a autonomia das cortes rabínicas, essa interdição funcionava com o estabelecimento de cortes rabínicas arbitrais, às quais as partes se submetiam voluntariamente (às vezes, de forma tão discreta que beirava a clandestinidade). As cortes arbitrais reproduziam o desenho dos antigos Tribunais Ordinários da período do Sinédrio, sendo compostas por três juízes, cada parte escolhendo um juiz e o terceiro sendo escolhido de comum acordo entre ambas.

Um importante princípio, estabelecido pelo Rabi Samuel, que gozava de imenso prestígio entre as comunidades da Diáspora, proclamava a regra de que os judeus deveriam submeter-se às leis do país em que se encontravam, desde que não colidissem com as leis judaicas - "dina demalchuta dina", ou seja, “a lei do estado é lei” (LEÃO, 1998, p. 31). Essa regra permitia aos judeus a flexibilidade necessária para viverem em países estrangeiros, sob normas estrangeiras, ao mesmo tempo em que preservavam um espaço à sua própria lei como nação de apátridas e exilados.

Qual o Direito aplicado por essas comunidades de exilados? A esta indagação, Leão responde:

O termo "Talmud" cujo significado literal é "aprendizado" ou "ensino" é comumente empregado para designar o Talmud Babilônico, cuja notoriedade sobressaiu através do tempo. De fato, o interesse que tem despertado e a extensão do Talmud Bavli devem-se ao fato de ele reunir não só matéria de "halachah" (lei), mas também, e principalmente (cerca de 2/3 do compêndio), "aggadah" (lendas, histórias de fundo moral), suscitando interessantes discussões e um grande desenvolvimento intelectual (...)

Na verdade, o "Talmud" constitui uma imensa biblioteca de leis e regulamentos produzida por um grande esforço de sábios durante vários séculos, que se caracteriza mais por ser o embasamento, a fonte de todo um sistema jurídico, que a partir dele ganhou um novo impulso.

(...) 
É possível um Direito sem Estado?

Ao longo do tempo, vários códigos, esses sim verdadeiros códigos legais, foram sendo feitos por sábios e rabinos, visando à condensação de todo o material de "halachah" existente no "Talmud". Assim, pode-se citar entre eles o de autoria de Issac Alfasi, inspirador do maior de todos os códigos, o "Mishné Torá" de Maimônides (século XII), o "Shulchan Aruch" de Josef Cairo (século XV), e o "Mapá” de Moisés Isserles (século XVI). Tais códigos sistematizaram e simplificaram as disposições da lei, elaboradas ao longo do tempo e inseridas no "Talmud", para uso dos leigos no seu dia-a-dia, uma vez que o "mar do Talmud" não era acessível ao povo em geral, dada a sua profunda erudição. (...)

Para dirimir os casos controvertidos que surgiam na Diáspora e que não possuíam uma disciplinização nos códigos existentes, criou-se mais uma fonte legal: as "responsas" ("sheelot u-tshuvot"). A "responsa" consistia numa consulta feita por um rabino, indivíduo ou comunidade que estava em dúvida acerca de algum preceito legal ou de alguma decisão a ser tomada, a um rabino conceituado como uma das maiores autoridades da época, sobre a questão duvidosa, sobre a qual a autoridade deveria dar o seu parecer. Foi-se formando assim uma verdadeira coleção jurisprudencial, que foi responsável pelo dinamismo do sistema judaico, uma vez que foi satisfazendo aos problemas gerados pela evolução dos tempos e pelos novos costumes das novas comunidades (LEÃO, 1998, p. 38-40).

Rodrigo Freitas Palma tenta sintetizar a experiência do Direito hebraico na Diáspora da seguinte forma:

Interessante notar que os israelitas foram, historicamente, perseguidos e menosprezados pelo considerável apego às suas leis. Durante o reinado de Xerxes I (485-465 a.C.) emanou do cetro persa o seguinte decreto:

No meio dos persas, em todas as províncias de teu reino, está espalhado um povo à parte. Suas leis não se parecem com as de nenhum outro e as leis reais são para eles letra morta. Os interesses do rei não permitem deixá-lo tranqüilo. Que se decrete, pois, a sua morte, se bem parecer ao rei e versarei aos seus funcionários, na conta do Tesouro Real, dez mil talentos de prata.

Infelizmente, o evento em questão não foi um acontecimento isolado. A nação [judaica] sofreu outras vezes por expressar sua religiosidade e inclinação para proclamar as normas dispostas em seu direito revelado. (...)

De qualquer forma, apesar de tudo, sobreviveu vigorosamente o Direito hebraico no decurso dos séculos. Os preceitos dogmático-jurídicos que o compõem inundaram as mentes e os corações desejosos de proclamar o ideal universal de justiça, visivelmente presente no corolário do decálogo. A luz irradiada por eles ainda cintila de forma inebriante no imaginário dos povos (PALMA, 2008, p. 23). 


\section{O Direito hebraico da Diáspora tem as características que o Normativismo aponta no Direito em geral?}

Kelsen aponta como característica central do Direito o fato de ser uma ordem social coercitiva, isto é, que se impõe aos indivíduos independentemente de e até contra a sua vontade:

a) O Direito: ordem de conduta humana

Uma teoria do Direito deve, antes de tudo, determinar conceitualmente o seu objeto. (...) Com efeito, quando confrontamos uns com os outros os objetos que, em diferentes povos e em diferentes épocas, são designados como "Direito", resulta logo que todos eles se apresentam como ordens de conduta humana. Uma "ordem" é um sistema de normas cuja unidade é constituída pelo fato de todas elas terem o mesmo fundamento de validade.

(...)

b) o Direito: uma ordem coativa

Uma outra característica comum às ordens sociais a que chamamos Direito é que elas são ordens coativas (...) Dizer que o Direito é uma ordem coativa significa que as suas normas estatuem atos de coerção atribuíveis à comunidade jurídica (KELSEN, 1996, p. 33-37).

Em outro lugar, o mesmo autor assinala:

Se as ordens sociais, tão extraordinariamente diferentes em seus teores, que prevaleceram em diferentes épocas e entre diferentes povos, são chamadas ordens jurídicas, poder-se-ia supor que está sendo usada uma expressão quase destituída de significado. O que o chamado Direito dos babilônios antigos poderia ter em comum com o direito vigente hoje nos Estados Unidos? O que a ordem social de uma tribo negra sob a liderança de um chefe despótico uma ordem igualmente chamada "Direito" - poderia ter em comum com a constituição da república suíça? No entanto, há um elemento comum que justifica plenamente essa terminologia e que dá condições à palavra "Direito" de surgir como expressão de um conceito com um significado muito importante em termos sociais. Isso porque a palavra se refere à técnica social específica de uma ordem coercitiva, a qual, apesar das enormes diferenças entre o direito da antiga Babilônia e o dos Estados Unidos de hoje, entre o Direito dos ashanti na África Ocidental e o dos suíços na Europa, é, contudo, essencialmente a mesma para todos esses povos que tanto diferem em tempo, lugar e cultura: a técnica social que consiste em obter a conduta social desejada dos homens através da ameaça de uma medida de coerção a ser aplicada em caso de conduta contrária (KELSEN, 2005, p. 26-28).

O Direito hebraico na Diáspora atende plenamente a essa caracterização. Como vimos acima, as cortes rabínicas no exílio exerciam em larga escala o direito de sanção. Não é preciso, portanto, nenhum esforço especial para concluir que essas características se encontram plenamente representadas no Direito hebraico na Diáspora, pelo menos na maior parte dos locais de exílio e na maior parte do tempo, como já vimos acima. 
Ainda assim, é preciso responder a uma possível objeção: poder-se-ia dizer que a autoridade do Direito hebraico era uma autoridade de fato, mas não de Direito, na distinção conceitual feita por Kelsen:

\section{c. Autoridade jurídica e de facto}

A partir do ponto de vista da jurisprudência normativa, a ordem de pagar impostos difere da ameaça do bandido e do pedido do amigo pelo fato de apenas a ordem fiscal ter sido emitida por um indivíduo autorizado por uma ordem jurídica pressuposta como válida. (...) Ele paga o imposto considerando o comando de pagar como um ato emitido por um indivíduo autorizado por uma ordem que o contribuinte considera válida. (...) Sociologicamente, a diferença decisiva entre os três atos é o fato de que a conduta do contribuinte é determinada - ou pelo menos acompanhada - pela idéia de uma ordem válida, de norma, dever, autoridade, ao passo que sua conduta nos outros casos não é determinada ou acompanhada por tal idéia (idem, p. 254-255).

É evidente que o comando emanado das cortes rabínicas era visto, sim, pelos judeus no exílio como "uma ordem válida, de norma, dever, autoridade" e que esse comando era visto como um ato emitido por um indivíduo autorizado por uma ordem que o jurisdicionado considerava válida, por razões religiosas, étnicas ou culturais. A autoridade rabínica era vista pelos judeus no exílio como uma autoridade jurídica e não uma mera autoridade de fato. Tanto assim que o reconhecimento de outras ordens jurídicas a que deviam obedecer foi um comando rabínico, emitido, como já mencionamos, pelo Rabi Samuel, e essas outras ordens só tinham reconhecida sua autoridade quando não contraditavam as leis do Direito hebraico ( $c f$. visto acima).

Revelador da autoridade de que esse Direito era investido entre os judeus da Diáspora é o fato de que, onde a possibilidade de impor sanções foi subtraída às cortes rabínicas pelos governos sob os quais se encontravam exilados os judeus, a apresentação dos casos às cortes rabínicas arbitrais passasse a ser a norma de conduta mais comum entre os exilados. Na verdade, recolhendo-se à conciliação privada, os litigantes contornavam, de certa forma, as disposições estatais que vedavam a aplicação do Direito hebraico, de forma a prestigiar e reconhecer a competência das cortes rabínicas como seus juízes naturais. Dessa forma, o Direito hebraico não perdeu em nenhum momento sua eficácia, atendendo a outra característica central apontada por Kelsen: "A eficácia do Direito pertence ao domínio da realidade e é muitas vezes chamada de poder do Direito. (...) O Direito é, segundo a teoria aqui desenvolvida, uma ordem ou organização específica de poder" (idem, p. 177). 


\section{6 É possível a existência de um Estado sem território, na ótica Normativista?}

Um argumento que poderia ser oposto à argumentação que vimos desenvolvendo aqui é que seria possível falar da existência do Estado hebreu mesmo sem que esse Estado dispusesse de um território, o que, se fosse possível, mudaria inteiramente o rumo do diálogo que vimos travando aqui com a tese normativista da unidade do Estado e do Direito.

Entretanto, o território não é, na visão normativista, apenas um acessório que o Estado pode ter ou não ter, sem deixar de ser Estado. A visão de Kelsen, principal expoente dessa corrente, não é de que o território seja um elemento sociológico, um componente factual do estado. O território, para Kelsen, é visto como um elemento jurídico que integra essencialmente o Estado e que "pode ser definido como o domínio espacial de vigência de uma ordem jurídica estadual”( KELSEN, 1996, p. 319), ou seja, se não existe território, não há um domínio espacial onde o Direito estatal possa existir. Para que não haja dúvidas de que, para os normativistas, o território era um elemento essencial, ou seja, sem o qual o Estado não existe, podemos citar as palavras do próprio Kelsen:

Desta forma, o Estado, cujos elementos essenciais são a população, o território e o poder, define-se como uma ordem jurídica relativamente centralizada, limitada por seu domínio espacial e temporal de vigência, soberana ou imediata relativamente ao Direito internacional e que é, globalmente ou de um modo geral, eficaz (idem, p. 321, grifo nosso)

Ademais, é de se ressaltar que o normativismo, no seu afã unificador, declarou também a unidade do Direito internacional e do Direito estatal. Portanto, um Estado individual e o seu Direito estatal são parcelas da ordem jurídica internacional:

Se partirmos do Direito internacional como uma ordem jurídica válida, o conceito de Estado não pode ser definido sem referência ao Direito internacional. Visto desta posição, ele é uma ordem jurídica parcial, imediata em face do Direito internacional, relativamente centralizada, com um domínio de validade territorial e temporal jurídico-internacionalmente limitado (...) (idem, p. 377).

Kelsen tira as conseqüências dessa visão normativista da unidade do Direito internacional e do Direito estatal:

Isso significa que, segundo o Direito internacional, cada Estado fundamentalmente apenas pode aparecer revestido da sua qualidade de aparelho de coerção dentro de seu próprio domínio territorial, isto é, dentro do território que lhe é atribuído pelo Direito internacional; ou, para falar sem recorrer a imagens, que a ordem jurídica do Estado singular apenas deve estatuir os seus atos de coerção específicos para o espaço de validade que jurídico-internacionalmente lhe é reservado e que estes atos de coerção apenas podem ser estabelecidos sem ofensa do direito internacional dentro deste espaço (idem, $\mathrm{p}$. 376 , grifos nossos). 
Portanto, não restam dúvidas de que, na ótica normativista, que é a que nos interessa neste trabalho, é impossível a existência de um Estado sem território que lhe seja reconhecido como âmbito de validade espacial de sua ordem jurídica pelo Direito internacional. Portanto, na própria ótica normativista, não se pode falar em um Estado hebraico na época da Diáspora.

\section{A ótica de outras correntes jusfilosóficas}

A identificação estrita entre Direito e Estado é uma das características que distinguem o positivismo normativista das correntes de filosofia do Direito anteriores a ele, em especial os defensores do direito natural ou jusnaturalismo, contra quem se volta com mais intensidade o gume da crítica positivista.

Para as correntes jusnaturalistas, o Direito tinha como fonte a revelação divina ou a lei moral natural inerente ao ser humano. O Estado apenas elaborava o direito positivo, que tinha como parâmetro o direito natural e que só era legítimo se estivesse em sintonia com este. Assim, para essas correntes, o Direito existia anteriormente ao Estado, como Direito ideal e imutável. Para os jusnaturalistas, em conseqüência, a sobrevivência do Direito hebraico à destruição do Estado hebreu não representa um problema teórico, mas apenas uma questão histórica, explicar as circunstâncias que tornaram possível essa cisão.

Ademais, pelo menos uma corrente filosófica contemporânea e muito próxima ao positivismo normativista, a Teoria Egológica, do jurista argentino Carlos Cossio, identifica o Direito não com a norma nem com o Estado, mas com a conduta humana. O Direito, para Cossio, é a conduta humana em relação intersubjetiva, e existe sempre que dois ou mais seres humanos se relacionam, e, portanto, antes mesmo do surgimento do Estado. A norma, nessa visão, é um conceito é um "conceito apto para pensar a conduta como conduta" (COSSIO, 1950). O Estado sequer cria o Direito, apenas pode modificar o direito preexistente, pois sempre se encontrará um Direito anterior. Portanto, também para o egologismo a sobrevivência do Direito hebraico nas circunstâncias da Diáspora não se constitui em um problema teórico.

\section{Conclusão}

Leão sintetiza com muita felicidade a trajetória do Direito hebraico durante o período da Diáspora:

Inegavelmente, durante os anos de Dispersão, em que o povo judeu viveu espalhado pelo mundo, sem um Estado próprio, foi a lei hebraica que garantiu a sobrevivência da fé judaica. Como pura tradição religiosa, sua vigência independia de um poder estatal institucionalizado, pois sua aceitação tinha por fundamento a crença num D’us único, 
revelador de normas imprescindíveis para o bem-estar e a prosperidade do povo judeu (LEÃO, 1998, p. 40)

Há, pois, uma contradição evidente entre o conceito da unidade do Estado e do Direito, que está no coração da teoria normativista, e o fato histórico da sobrevivência e aplicação do Direito hebraico na ausência de um Estado hebraico. O Direito hebraico, como vimos, atende aos requisitos para ser considerado, a todos os títulos, como Direito, nos termos mesmo adotados pelo positivismo normativista. Por outro lado, é incontestável a evidência histórica de que esse Direito continuou a ser aplicado durante a Diáspora, quando o Estado judeu foi destruído pelo império romano e seus cidadãos espalhados pelo mundo como exilados. Nessa época, não existia um Estado hebraico, mas existia de forma inequívoca um Direito hebraico que era válido e eficaz e foi aplicado continuamente por todo o tempo da Grande Dispersão.

A experiência histórica do povo judeu, portanto, milita contra aquela concepção do positivismo normativista, e, na medida em que este pretende ser visto como uma concepção científica do Direito, não pode se recusar à prova da experiência, que é o método central do pensamento científico. Entendemos que a experiência histórica da sobrevivência do Direito hebraico durante a Diáspora, sem a existência de um Estado hebreu correspondente, refuta a tese esposada pelo positivismo normativista da unidade indissociável entre Direito e Estado.

A argumentação desenvolvida nesse texto, portanto, pode ser expressa como um silogismo:

\begin{tabular}{|} 
premissa maior: \\
Segundo o normativismo, o Estado e o Direito constituem uma unidade indissociável; \\
premissa menor: \\
no entanto, é fato histórico a existência de um Direito hebraico válido e eficaz, durante a Diáspora, \\
dissociado de um Estado hebreu, inexistente nessa época; \\
conclusão: \\
logo, esse fato histórico refuta a tese normativista da unidade indissociável do Direito e do Estado.
\end{tabular}

Encerramos a nossa argumentação, pois, à moda dos geômetras: era o que queríamos demonstrar.

\section{Referências}

COSSIO, Carlos. Teoria egológica e teoria pura do direito. In: Revista Forense, v. CXXIX, ano XLVII, fasc. 563, Rio de Janeiro, maio de 1950.

GILLISSEN, John. Introdução histórica ao direito. 4 ed. Lisboa: Fundação Calouste Gulbenkian, 2003. $813 \mathrm{p}$.

KELSEN, Hans. Teoria geral do direito e do Estado. 4 ed. São Paulo: Martins Fontes, 2005. 637 p. . Teoria pura do direito. 5. ed. São Paulo: Martins Fontes, 1996. 427 p. 
LEÃO, Sinaida De Gregório. A influência da lei hebraica no direito brasileiro, casamento e divórcio. Rio de Janeiro: Lumen Juris, 1998. 262 p.

MACHADO NETO, A. L. Compêndio de introdução à ciência do direito. 5. ed. São Paulo: Saraiva, 1984. $281 \mathrm{p}$.

MEDEIROS DA SILVA, Jorge. O direito penal dos hebreus. Revista Justitia, São Paulo, v. 41, n. 107, out./dez. 1979.

PALMA, Rodrigo Freitas. Manual elementar de Direito hebraico. 1. ed. Curitiba: Juruá, 2008. 93 p. 